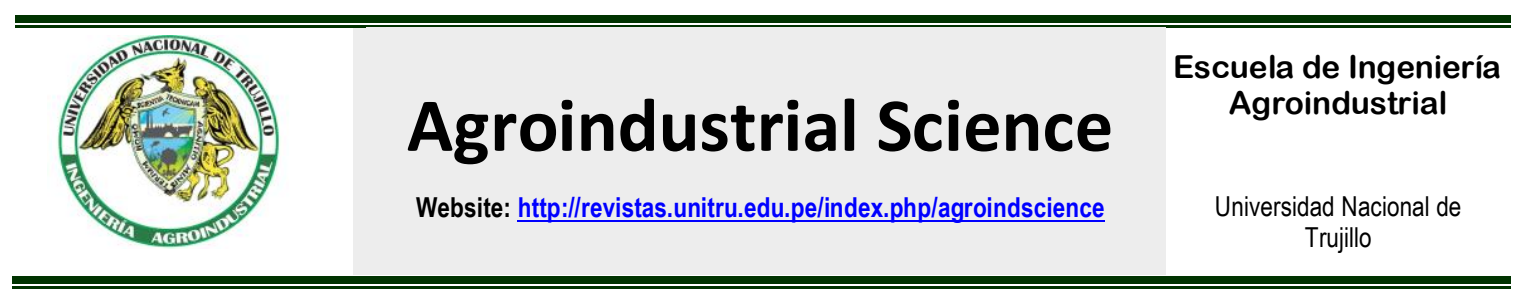

\title{
Storage evaluation of a functional food with skimmed milk enriched with fatty acids of Sacha Inchi (Plukenetia volubilis L.)
}

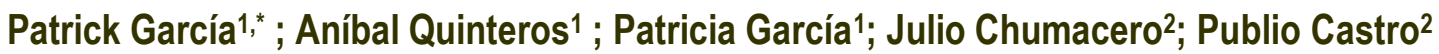 \\ 1 Facultad de Ingeniería Agroindustrial, de la Universidad Nacional de San Martín, Tarapoto, San Martín, Perú \\ 2 Facultad de Agronomía, Universidad de Buenos Aires. Av. San Martín 4453, Buenos Aires, Argentina.
}

\begin{abstract}
The aim of this study was obtain a semi skim milk enriched with sacha inchi oil (Plukenetia volubilis L.), with sensory acceptability and a suitable storage container. The raw materials used were: fresh semi skim milk of creole cow and virgin sacha inchi oil. The content of polyunsaturated fatty acids raised from $2.8 \%$ to $3.0 ; 3.2 \%$ and $3.4 \%$ according to the treatment. It was evaluated the sensory microbiological properties of the semi skim milk during its storage period of 30 days. The packaging material used were high density polyethylene container and glass container. The best formulation for semi skim milk was the correspond to $3 \%$ of fatty acids stored in glass container which obtained values of: Taste 2.2; Color 2.1; Texture 2.2 and Appearance 2.2 on a maximum of 5.0 units. It is concluded that the production of semi skim milk enriched with fatty acids of sacha inchi is feasible.
\end{abstract}

Keywords: sacha inchi oil; semi skim milk, sensory evaluation, shelf life.

\section{Introduction}

During last years, the consumer has developed a growing interest in the consumption of healthy foods with functional activities. In this context, there is a huge interest in modifying the fatty acid profile (FA) of milk, which contains $70 \%$ saturated FA to a lower one (Jenkins and McGuire, 2006). The saturated FA tend to increase the plasma cholesterol levels raising the incidence of cardiovascular diseases ( $\mathrm{Hu}$ et al., 2001), deriving in the need of modify its profile to a lower saturated one.

In addition, several polyunsaturated FA have shown to have beneficial effects for human health. Maybe, the best example has been the development of the concept and marketing of foods rich in omega-3 FA, because these products have shown cardioprotective effects in humans (Kris-Etherton et al., 2002; Eritsland, 2000, Rosenfeld et al., 2009). The development of these products have based in the modification of the relation between omega- 6 : omega -3 in the human diet, which is currently 10 : 1, when the official recommendations set at $4: 1$. This impulse has motivated the commercialization of dairy products enriched through the addition of fiber, vitamins, and fatty acids, among other nutrients, making it a functional food (Díaz et al., 2004; Saxelin et al., 2003). In that sense the Sacha
Inchi (Plukenetia volubilis L.), also known as Inca peanut, it is a fickle, climbing, semi-wild, oleaginus plant that grows mainly in the Peruvian Amazon, it is known by the Peruvian natives from thousands of years. Such is its natural power for the benefit of health, that it is essential to include it in our lives. It is oily seed rich in amino acids and essential fatty acids and fat-soluble vitamins. Sacha inchi oil is characterized by its high levels of polyunsaturated fatty acids (Omega $3,6,9)$ in a greater proportion than $80 \%$, attributed to a Cardio-Healthy Food in the prevention of heart diseases (Torres et al., 2015; Castaño et al., 2011).

Previous studies showed that the derivatives of milk were enriched with fatty acids from chia or flax oil (Ruíz and Puyalto, 2017). For this reason, the importance of this research lies to obtain semi skim milk enriched with fatty acids of Sacha Inchi and constitute an alternative functional food.

\section{Material and methods}

\section{Raw material}

The present research used as raw material fresh milk from the districts of Cuñumbuque, Bellavista and Juanjui and virgin sacha inchi oil of Shanantina S.A.C. 


\section{Conditioning of sacha inchi oil}

To the deodorization process, the oil was poured into a filtration tower containing activated carbon; and filter paper on the top and down. After this process, the sacha inchi oil lost their characteristic sharp smell; In addition, the flavor of the virgin oil was reduced partially.

\section{Development of enriched skim milk}

The process began with the receipt of fresh milk: from the stables. The fresh milk was collected directly from the stables of the sector. In the stables the milk was stored in cold tanks at $4{ }^{\circ} \mathrm{C}$. The fresh milk presented a suitable temperature of $7-8^{\circ} \mathrm{C}$ at the time of the arrival at the plant. Subsequently, the filtration was carried out in order to avoid the entry of coarse particles of milk into the process. After that, the fresh milk circulated through the pasteurizer, which is a plate heat exchanger with three levels of heating, through the circulation of hot water counter flow. The hot water is obtained through a heat exchanger that operates with steam as heating source, the temperature and the permanency time in the pasteurizer must be controlled. In this case, the temperature was raised until $73^{\circ} \mathrm{C}$ and the flow was regulated in order the milk remained 23 seconds inside the pasteurizer. Once the pasteurized milk was obtained, the skimming stage is carried out: In this stage it was necessary to use the centrifugal separator which has conical disks equipped with distribution holes that are vertically aligned. Milk is introduced through these holes gradually to determine the percentage to be removed and under the influence of centrifugal force, the fat is separated. Fat globules, having a lower density than semi skim milk, move inward (the axis of rotation) while the semi skim milk moves outward, and from there through a channel to the conical tip of the container. The milk was conditioned at a temperature of $32{ }^{\circ} \mathrm{C}$, in order to perform the percentage incorporation of sacha inchi oil (Plukenetia volubilis L.) and start a dispersion process of the milk fat globule to facilitate the solubility with the fatty components of the Sacha Inchi (Plukenetia volubilis L.) oil, to avoid its separation after a prolonged period of rest.

Finally, the semi skim milk enriched with sacha inchi (Plukenetia volubilis L.) oil to direct consumption was packaged and warehoused at surrounding temperature and temperatures between $2{ }^{\circ} \mathrm{C}$ to 8 ${ }^{\circ} \mathrm{C}$.

\section{Sensory analysis}

Sensory evaluations were carried out on the final products, milk enriched with Sacha Inchi (Plukenetia volubilis L.) oil in substitution percentages of 3.0 ;
3,$2 ; 3.4 \%$; at seven-day intervals during a month of warehousing between 2 to $8{ }^{\circ} \mathrm{C}$ against the control cow's milk (without preservative and vegetable oil). This was made to describe the organoleptic quality that guarantees the preservation of the quality attributes of the enriched milk with sacha inchi (Plukenetia volubilis L.) oil packed in high density polyethylene bottles and glass bottles. The evaluations were made by a group of trained panelists, considering the existence of 09 treatments and 02 factors. This analysis was based on a hedonic scale of 5 points, where 1 is "I do not like" or "dislike me", 2 is "acceptable", 3 is "I like it", 4 is "I like very much it a lot" and 5 is "I like it a lot".

\section{Microbiological analysis}

The microbiological analysis was carried out in order to determine if the conservation conditions have allowed the presence of groups and concentrations of microorganisms that can damage or alter the quality of the product. The microorganisms that are microbial quality indicators are organisms, or metabolic products of these, whose presence at certain levels in food is used to evaluate the quality of the food or to predict the durability of the food (Jay, 2002). The analyzes performed were the count of viable aerobic mesophiles (ISO-4833-2003) and total coliforms (ISO-4831-2006).

\section{Results and discussion}

\section{Characterization of fresh milk, skimmed milk and fortified skim milk}

The results of the physicochemical analysis of the samples of fresh milk from the areas harvested to the treatments are shown in Table 1.

Table 1

Physicochemical characterization of fresh milk

\begin{tabular}{cccccc}
\hline $\begin{array}{c}\text { Sample } \\
\text { milk }\end{array}$ & $\rho(\mathrm{g} / \mathrm{ml})$ & $\mathrm{Dc}^{\circ}$ & $\mathrm{pH}$ & $\begin{array}{c}\text { Fat } \\
(\%)\end{array}$ & $\begin{array}{c}\text { total solids } \\
(\%)\end{array}$ \\
\hline Cuñumbu & 1,0298 & 14,0 & 6,78 & 3,20 & 12,18 \\
Bellavista & 1,0306 & 14,0 & 6,76 & 3,30 & 12,62 \\
Juanjui & 1,0306 & 14,5 & 6,72 & 3,10 & 11,85 \\
\hline
\end{tabular}

The milk samples analyzed from the 3 collection centers were within the appropriate values according to NTP 202.008 (density), NTP 202.126 (fat), NTP 202.116 (milk acidity), NTP 202.118 (total solids).

After the fresh milk had the skimming process, the milk fat was standardized at a value of $2.80 \%$; from this amount the calculations were made to add the virgin sacha inchi (Plujenetia volubilis L) oil. Table 2 shows the physicochemical analysis of skimmed milk. 
Table 2

Physicochemical characterization of skimmed milk.

\begin{tabular}{ccccc}
\hline Sample & $\rho(\mathrm{g} / \mathrm{ml})$ & $\mathrm{Dc}^{\circ}$ & $\mathrm{pH}$ & $\begin{array}{c}\text { fat } \\
(\%)\end{array}$ \\
\hline $\begin{array}{c}\text { skimmed } \\
\text { milk }\end{array}$ & 1,0291 & 14,7 & 6,76 & 2,80 \\
\hline
\end{tabular}

Physicochemical results such as $\mathrm{pH}$ and acidity were found within the limits allowed for milk, it is also observed that the density of skimmed milk was affected by the decrease in fat percentage to $2.80 \%$, however, these levels are permissible for milk. From this fat value, sacha inchi oil was added in $0.2 \% ; 0.4 \%$ and $0.6 \%$ fat percentages to obtain milks with a percentage of fat of $3.0 \% ; 3.2 \%$ and $3.4 \%$ respectively. The values of enriched skim milk are shown in Table 3.

Table 3

Physicochemical characterization of enriched skim milk.

\begin{tabular}{ccccc}
\hline Skim milk & $\rho(\mathrm{g} / \mathrm{ml})$ & $\mathrm{Dc}^{\circ}$ & $\mathrm{pH}$ & $\begin{array}{l}\text { Fat } \\
(\%)\end{array}$ \\
\hline Sample 1 & 1,0298 & 15,0 & 6,68 & 3,0 \\
Sample 2 & 1,0304 & 15,0 & 6,66 & 3,2 \\
Sample 3 & 1,0306 & 15,5 & 6,64 & 3,4 \\
\hline
\end{tabular}

\section{Sensory analysis of enriched skim milk}

The results of the sensory analysis applied to the smell for skimmed milk enriched with sacha inchi oil can be seen in Figure 1.

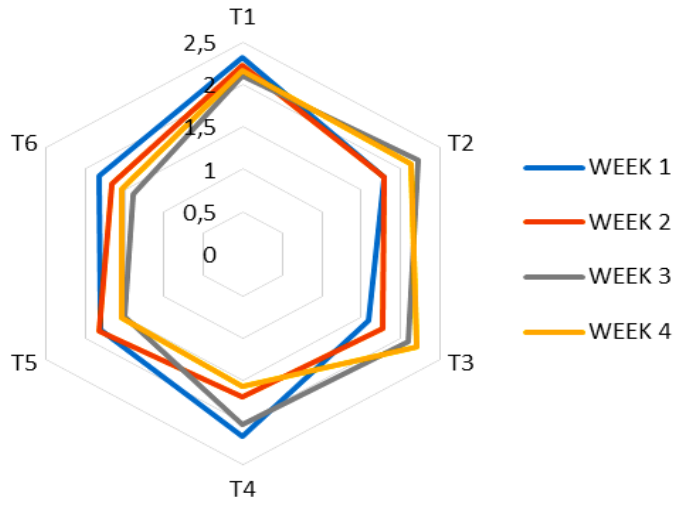

Figure 1. Results of the sensory analysis of smell.

The data obtained for the smell were validated by the analysis of variance with a significance level of $\mathrm{pV}=0.01$ with coefficient of determination higher than $85 \%$, showing that there is a high relationship and correlation between the treatments studied to this study level (Calzada, 1982).

Similarly, through the Tukey test it is validated the existence of significant differences between the treatments, being the $\mathrm{T} 1$ treatment with an average value of 2.33 (treatment at $3 \%$ of fat substitution, in a glass container), which obtained the highest value in smell during all weeks analyzed, being cataloged as the best treatment. On the other hand, the T6 treatment with an average value of 1.60 (with a percentage of $3.2 \%$ substitution in high density polyethylene packaging) is the treatment that has the lowest value and the lowest stability in terms of smell.

Regarding the color, the results of its evaluation can be seen in Figure 2.

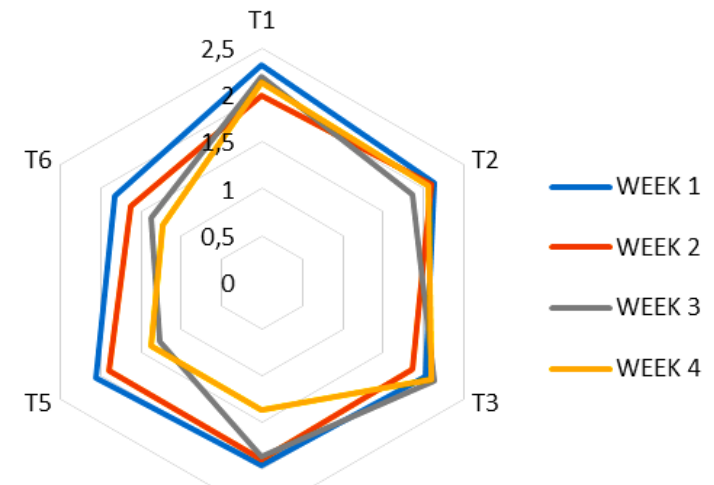

T4

Figure 2. Results of the sensory analysis of color.

From the results of Figure 2 for the color, the variance analysis showed that there are significant differences between the treatments with a level of significance of $\mathrm{pV}=0.01$ and a coefficient of determination greater than $90 \%$. Moreover, through Tukey test it was determined that there are significant differences between the samples, where the $\mathrm{T} 1$ treatment (percentage of $3 \%$ fat substitution, in glass container) has an average value of 2.16 , it is the one that obtained the highest value in color, being cataloged as the best of the treatments, this does not differ significantly with T2 treatment (with percentage of substitution to $2.04 \%$ in glass containers). The treatment with the lowest value was T6 (with a percentage of substitution of $3.4 \%$ in PET packaging) with an average of 1.53). Figure 3 shows the results of sensory analysis of flavor.

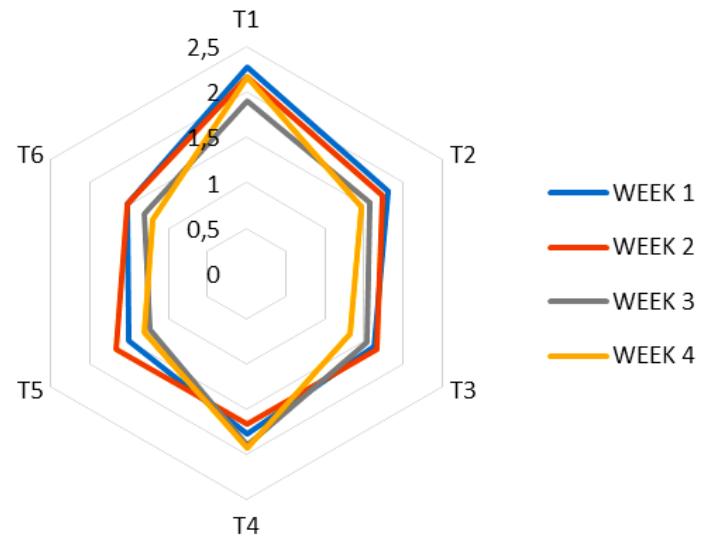

Figure 3. Results of the sensory analysis of flavor. 
When variance analysis of favor was made, it was obtained significant differences between treatments with a significance level of $\mathrm{pV}=0.01$ and $\mathrm{a}$ coefficient of determination greater than $95 \%$ during each week; this showed that there is a high relationship and correlation between the treatments studied.

On the other side, the Tuckey test results showed that there are significant statistical differences between treatments, where the $\mathrm{T} 1$ (of treatment with $3 \%$ of fat substitution, in glass container) with value of average 2.27; is the one that obtained the highest value in the flavor during the weeks of evaluation and was classified as the best treatment, this did not differ statistically from the T2 (with substitution percentage of $3.2 \%$ in glass container ) with an average value of 1.80 , who has statistical similarity with $\mathrm{T4}$, (with substitution percentage of $3 \%$ in PET packaging) with an average of 1.77 and with T3 (with substitution percentage of $3.4 \%$ in packaging of glass) with an average value of 1.63 . The T5 (with substitution percentage of $3.2 \%$ in PET packaging) with an average of 1.50; is the one that obtained the lowest value, like the T6 (with substitution percentage of $3.4 \%$ in PET packaging) with an average value of 1.53 ; who present statistical equality among themselves.

Regarding the body (Figure 4), the variance analysis through the weeks showed significant differences between treatments with a significance level of $p V=0.01$ and a coefficient of determination higher than $95 \%$, demonstrating that there is a high relationship and correlation between studied treatments, with a coefficient of variability (CV) of $4.02 \%$.

T6

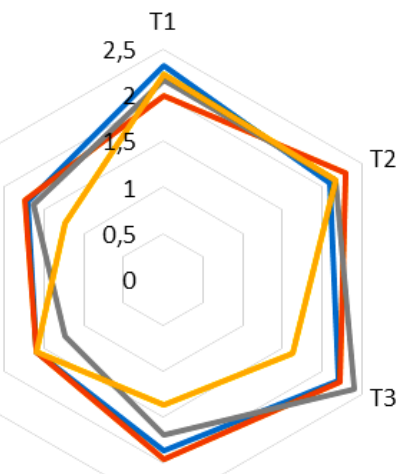

$\mathrm{T} 4$

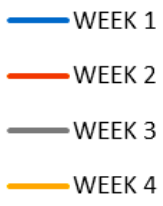

T5

Figure 4. Results of the sensory analysis of body.

Regarding the microbiological analysis of the enriched milk packaged in polyethylene bottles (HDPE) and glass both showed to be suitable for human consumption after a month of storage for being within the permissible limits of acceptance for human consumption (Table 4).
Table 4

Microbiological result of milk packed in HDPE bottle and glass bottle.

\begin{tabular}{ccc}
\hline $\begin{array}{c}\text { Enriched milk } \\
\text { packaged } \\
\text { bottle }\end{array}$ & $\begin{array}{c}\text { Colony } \\
\text { forming unit } \\
\left(<5^{*} 10^{4} \mathrm{CFU} / \mathrm{ml}\right)\end{array}$ & $\begin{array}{c}\text { Total coliforms } \\
(<10 \mathrm{CFU} / \mathrm{ml})\end{array}$ \\
\hline HDPE & $7^{*} 10^{4} \mathrm{CFU} / \mathrm{ml}$ & $5 \mathrm{CFU} / \mathrm{ml}$ \\
Glass & $1^{*} 10^{4} \mathrm{CFU} / \mathrm{ml}$ & $<1 \mathrm{CFU} / \mathrm{ml}$ \\
\hline
\end{tabular}

For later studies, it is recommended to perform accelerated tests to determine the maximum period by which the milk enriched with fatty acids remains innocuous and also retains most of its organoleptic and nutritional properties. Due to during the development of new products, it is vitally important to validate the expiration date of the product issued.

\section{Conclusions}

According to the results of the sensory tests, the formula for skim milk enriched with acid grades of sacha inchi with better acceptance was the T4, with a fat percentage of $3 \%$ in glass container. The glass container is the most suitable because it guarantees the safety of the product for a period of 30 days without affecting its sensory attributes and microbials.

It is possible to make partial replacement of fat milk with the sacha inchi oil in order to enrich the nutritional value of the food without altering its components to ensure the welfare of those who consume it.

\section{References}

Calzada, B. 1982. Métodos Estadísticos. Universidad Nacional Agraria la Molina. Lima, Perú.

Castaño, D.; Valencia, M.; Murillo, E.; Mendez, J.; Joli, J. 2011. Composición de ácidos grasos de sacha inchi (Plukenetia volúbilis linneo) y su relación con la bioactividad del vegetal. Revista Chilena de Nutrición 39(1): 45-52.

Díaz, B.; Sosa, M.; Vélez, J. 2004. Efecto de la adición de fibra y la disminución de grasa en las propiedades fisicoquímicas del yogur. Revista Mexicana de Ingeniería Química 3: 287-305.

Eritsland, J. 2000.Safety considerations of polyunsaturated fatty acids. Am. J. Clin. Nutr. 71: 197S-201S.

Hu, B.; Manson, J.; Willet, W. 2001. Types of dietary fat and risk of coronary heart disease: a critical review. J Am. Coll. Nutr. 20: 5-19.

Jay, J. 2002. Microbiología Moderna de los Alimentos. Editorial Acribia S.A. 4 edición, 615 pp.

Jenkins, T.; McGuire, M. 2006. Major Advances in Nutrition: impact on Milk Composition. Journal of Dairy Science 89: 1302 -1310.

Kris-Etherton, P.; Harris, W.; Appel, L. 2002. Fish Consumption, Fish Oil, Omega - 3 Fatty Acids, and Cardiovascular Disease, for the Nutrition Committee. Circulation 106: 2747-2757.

Ruíz, J.; Puyalto, M. 2017. Producción de leche enriquecida con omega 3. Ganadería. Disponible en:

https://norel.net/es/system/files/leche\%20 enriquecida\%20omega3. pdf

Saxelin, M.; Korpela, R.; Máyrá-Makiren, A. 2003. Introduction: classifying functional dairy products. In Functional Dairy Products, pp. 1-16, CRC Press. Cambridge, Reino Unido.

Torres, C.; Obregon, A. 2015. Nivel de sustitución de leche de saca inchi (Plukenetia Volubilis) en la elaboración de yogurt batido. 
XXVIII Congreso Colombiano de Ingeniería Química. Bogotá D.C., Colombia. Disponible en:

http://www.academia.edu/20395996/NIVEL_DE_SUSTITUCION_D E_LECHE_DE_SACHA_INCHI
Rosenfeld, E.; Beyerlein, A.; Hadders-Algra, M.; Kennedy, K.; Singhal, A.; Fewtrell, M.; Lucas, A.; Koletzko, B.; Von Kies, R. 2009. IPD meta-analysis shows no effect of LCPUFA supplementation on infant growth at 18 months. Acta Pediatr. 98: 91-97. 